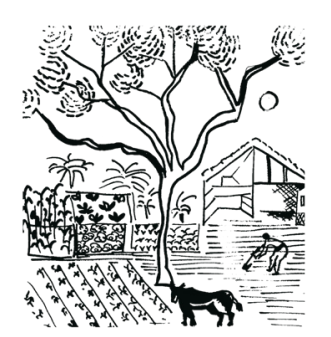

Vol. 24 N.1 de 2021 ISSN: 1516-8182

Recebimento: 02/11/2020

Aceite: 01/01/2021

DOI: 10.25059/2527-2594/retratosdeassentamentos/2021.v24i1.471

\title{
Sistema participativo de garantia Orgânicos Jequitinhonha: o desafio da participação em tempos de pandemia
}

\author{
Aloísia Rodrigues Hirata ${ }^{1}$ \\ Sueli Gomes Fernandes ${ }^{2}$ \\ Luiz Carlos da Rocha ${ }^{3}$ \\ Sonia Maria Pessoa Pereira Bergamasco ${ }^{4}$ \\ Ademilson Gonçalves da Silva ${ }^{5}$ \\ Dário Oliveira ${ }^{6}$ \\ Vanilde Ferreira de Souza-Esquerdo ${ }^{7}$
}

Resumo: O Sistema Participativo de Garantia (SPG) é uma metodologia de avaliação da conformidade orgânica baseada na participação ativa dos atores interessados que se organizam em rede. A pandemia da Covid-19 impôs diversas restrições de convívio social e, com isso, as visitas de pares e de verificação, principal mecanismo de controle social utilizado pelos SPGs, ficaram suspensas em 2020. Visando manter a dinâmica de interação e ainda contribuir para diminuir os impactos do isolamento social na vida dos agricultores, o SPG Orgânicos Jequitinhonha desenvolveu um método de visitas remotas. O objetivo deste trabalho foi compreender como se deu essa adaptação e quais os resultados foram alcançados. Trata-se de uma pesquisa-ação, onde os autores participaram ativamente da implantação da metodologia pesquisada. Destacamos como resultados o controle social exercido de forma satisfatória em sistema remoto, a maior interação entre as famílias, a aprendizagem no uso das tecnologias digitais que eram consideradas inacessíveis pelos agricultores familiares do Vale do Jequitinhonha.

Palavras-chave: Certificação Participativa. Extensão Rural. Controle Social. SPG. Agricultura Familiar.

Jequitinhonha Organic Guarantee Participatory System: the Challenge of Participation IN TIMES OF PANDEMIC

\footnotetext{
${ }^{1}$ Doutoranda FEAGRI/UNICAMP; Técnica em Assuntos Educacionais IFSULDEMINAS. E-mail: aloisia.hirata@ifsuldeminas.edu.br

${ }^{2}$ M.Sc. em Ciências Agrárias/Agroecologia, Ass. Téc. Centro de Agricultura Alternativa Vicente Nica. E-mail: susuagro@ yahoo.com.br

${ }^{3}$ D.Sc. em Entomologia, Prof. Agroecologia e Entomologia do IFSULDEMINAS-Campus Inconfidentes. E-mail: luiz.rocha@ ifsuldeminas.edu.br

${ }^{4}$ Professora Doutora FEAGRI/UNICAMP. E-mail: soniaberga@yahoo.com

${ }^{5}$ Técnico em agropecuária. Ass. Técnico Centro de Agricultura Alternativan Vicente NicaE-mail: demagoncalves@hotmail. com

${ }^{6}$ M.Sc. em Produção Vegetal no Semiárido, Ass. Téc. Centro de Agricultura Alternativa Vicente Nica. E-mail: darioagronomia@hotmail.com

${ }^{7}$ Professora Doutora FEAGRI/UNICAMP. E-mail: Vanilde.esquerdo@feagri.unicamp.br
} 
Abstract: The Participatory Guarantee System (PGS) is an organic conformity assessment methodology based on the active participation of interested actors who organize themselves in a network. The Covid-19 pandemic imposed several restrictions on social interaction and, as a result, peer and verification visits, the main social control mechanism used by SPGs, were suspended in 2020. Aiming to maintain the dynamics of interaction and also contribute to reduce the impacts of social isolation on the lives of farmers, the PGS Orgânicos Jequitinhonha developed a method of remote visits. The objective of this work was to understand how this adaptation took place and what results were achieved. It is an action research, in which the authors actively participated in the implementation of the researched methodology. We highlight as results the social control satisfactorily exercised in a remote system, greater interaction between families, learning in the use of digital technologies that were considered inaccessible by family farmers in Vale do Jequitinhonha..

KeYwords: Participatory Certification. Rural Extension. Social Control. Gsp. Family Farming.

\section{INTRODUÇão}

O Sistema Participativo de Garantia (SPG), também conhecido como certificação participativa, é uma metodologia de avaliação da conformidade orgânica que se baseia na participação ativa de todos os atores envolvidos ou interessados no processo de produção e na garantia da qualidade orgânica. O Brasil possui 27 SPGs, que juntos são responsáveis por quase 8.000 agricultores e agricultoras orgânicos certificados (BRASIL, 2020).

Em 2016, na região Nordeste de Minas Gerais, conhecida como Alto Vale do Jequitinhonha, foi constituído o SPG Orgânicos Jequitinhonha. O objetivo para a constituição deste SPG estava relacionado a proporcionar aos agricultores e agricultoras agroecológicos(as) desta região o acesso aos mercados para produtos orgânicos assim como fortalecer as práticas agroecológicas e associativistas e promover a construção do conhecimento agroecológico. Após a sua constituição, o SPG teve seu Organismo Participativo de Avaliação da Conformidade (OPAC) credenciado junto ao Ministério da Agricultura, Pecuária e Abastecimento (MAPA). O SPG Orgânicos Jequitinhonha tem como base as associações relacionadas às feiras nos municípios do Vale do Jequitinhonha (FERNANDES; OLIVEIRA; SILVA, 2020).

O processo de avaliação da conformidade orgânica, que culmina na certificação das unidades de produção, requer o envolvimento e a participação dos atores, especialmente dos agricultores e das agricultoras. A participação enquanto 
conquista é um processo que vai se construindo aos poucos e que nunca pode se dar por suficiente, nem acabado (DEMO, 2009). Nesse sentido, os SPGs, a cada dia, buscam construir diferentes formas de participação e de envolvimento dos agricultores e das agricultoras no processo de avaliação da conformidade orgânica. A participação ativa dos agricultores e das agricultoras, dos técnicos, dos consumidores e dos demais interessados nos diferentes espaços de construção do conhecimento e controle social, além de gerar credibilidade para o sistema participativo, ao mesmo tempo, pode ampliar o nível de confiança entre produtores e consumidores, o que leva à maior possibilidade de sucesso e longevidade de um SPG (HOME et al., 2017).

Em 2020, a participação presencial nas diversas atividades do SPG, em especial nas visitas de pares, ficou comprometida em função da pandemia da Covid-19. O Brasil registrou seu primeiro caso de contaminação pela Covid-10 em fevereiro de 2020 e, a partir de março do mesmo ano, o país decretou estado de emergência (AQUINO et al., 2020). As previsões alarmantes sobre o alto risco de contaminação e sobre o colapso no sistema de saúde pública, fez com que todos tivessem suas rotinas alteradas e buscassem o isolamento como principal medida de proteção. As aulas foram suspensas, muitos comércios foram fechados e boa parte dos serviços públicos foram transformados em home office. Uma situação inimaginável para a geração atual que impactou a vida da população, provocando profundas mudanças comportamentais, como por exemplo uma elevação na demanda por alimentos orgânicos, indicando uma maior preocupação dos consumidores com a saúde.

Em virtude desta situação, os agricultores e colaboradores do SPG Orgânicos Jequitinhonha se viram diante do seguinte impasse: como manter os processos participativos de avaliação da conformidade, realizar o controle social e as trocas de experiências sem provocar as aglomerações tão perigosas em tempos de pandemia da Covid-19?

Apesar da pandemia da Covid-19 ter provocado o aumento da demanda por alimentos orgânicos, também impôs uma série de limitações para a oferta desses alimentos, em especial à certificação por meio do SPG, visto que a participação ficou praticamente inviabilizada diante dos riscos de contaminação dos envolvidos. Além da preocupação com a segurança manifestada pelos agricultores, em março de 2020 o MAPA encaminhou aos OPACs do país um ofício com orientações a respeito do período de restrições para contenção do avanço da pandemia da Covid-19 (MAPA, 2020a). No Ofício, o MAPA manifesta a necessidade de uma ação cautelosa para a realização das atividades em campo que envolvem possibilidades de aglomeração. Em abril de 2020, atendendo solicitações do Fórum Brasileiro de SPGs e OCS (Organizações de Controle Social) um novo Ofício foi publicado restringindo a realização de procedimentos presenciais para a avaliação da conformidade orgânica 
(MAPA, 2020b). Esta situação estimulou e provocou a necessidade de inovar e de adaptar os mecanismos de controle social, ressignificando a participação.

Tendo em vista esta nova dinâmica de atuação dos SPGs em função da pandemia da Covid-19, este trabalho teve por objetivo descrever como se deu a adaptação nos procedimentos de controle social no SPG Orgânicos Jequitinhonha buscando compreender os impactos e os resultados alcançados.

\section{AS VISITAS DE PARES COMO MECANISMO DE AVALIAÇÃO DA CONFORMIDADE ORGÂAICA}

No processo de avaliação da conformidade orgânica em um SPG são utilizados diferentes mecanismos de controle social como reuniões, visitas de pares, visitas de verificação, registros e dias de campo nas unidades avaliadas. As visitas de pares constituem importante mecanismo de avaliação da conformidade orgânica. Segundo a Instrução Normativa No 19 de 2009, os objetivos da avaliação da conformidade nos SPGs são:

“[...]promover ações de natureza preventiva que garantam o cumprimento dos regulamentos da produção orgânica; identificar as não conformidades; assessorar os fornecedores para a resolução das não conformidades e para o aperfeiçoamento dos sistemas produtivos e promover a troca de experiências entre os participantes". (BRASIL, 2009)

Em geral, os SPGs realizam no mínimo duas visitas anuais, sendo a visita de pares e a visita de verificação. A diferença principal entre elas, é que na visita de verificação acontece a decisão da avaliação da conformidade, ou seja, é na visita de verificação que será decidido se a unidade de produção atende às normas legais e do OPAC, enquanto a de pares tem o objetivo de sugerir melhorias ou analisar respostas a eventuais não conformidades e monitorar o andamento das atividades da unidade produtiva por meio da participação dos membros do grupo (HIRATA et al., 2019). As visitas de pares extrapolam a função de controle de processos se configurando como um momento de busca coletiva de soluções onde acontecem a construção do conhecimento agroecológico por meio troca de experiência, saberes e formação educativa (KOMORI et al., 2020; CHAPARRO-AFRICANO; NARANJO, 2020; HIRATA et al., 2019).

O SPG Orgânicos Jequitinhonha é constituído por seis núcleos de agricultores e agricultoras, cada núcleo está circunscrito a uma localidade geográfica, em geral, em um município/comunidade rural. As visitas de pares ocorrem no primeiro semestre de cada ano e envolvem os membros do próprio núcleo sob a coordenação de um 
de seus membros. Nessas visitas há também a participação dos técnicos do Centro de Agricultura Alternativa Vicente Nica (CAV), que atuam como colaboradores do SPG. Analisando o intercâmbio de conhecimentos entre agricultores, Kirchner (2014) constatou que as visitas de pares constituem o principal mecanismo de intercâmbio de saberes dos SPGs.

Além de servir como instrumento de controle social e ferramenta para a construção do conhecimento agroecológico ressalta-se ainda que as visitas de pares constituem uma excelente oportunidade para fortalecer as relações sociais no campo por meio da maior interação entre famílias e, conforme destacado por Komori et al. (2020), a motivação vivenciada nas relações solidárias durante o desenvolvimento das visitas de pares cria vínculos entre as famílias. Esses vínculos fortalecem as relações de confiança entre os pares, princípio básico dos SPGs, além de contribuir para a criação de espaços de aprendizagem, convivência e diálogo, tão necessários no meio rural.

\section{Contexto Regional de constituição do SPG Orgânicos JEQUITINHONHA}

O Vale do Jequitinhonha está localizado na região Nordeste do estado de Minas Gerais e há predominância da agricultura familiar nos municípios que compõe esta localidade. A produção de hortaliças tem uma abrangência temporal maior e nos casos em que há a disponibilidade de água, a produção ocorre durante todo o ano. Nos processos produtivos ligados à agricultura familiar da região, o emprego de tratores, adubos químicos sintéticos e agrotóxicos é baixo e mesmo nas áreas convencionais há a preocupação com a produção sustentável de alimentos (RIBEIRO et al., 2014). Este pensamento é traduzido nas práticas rotineiras de agricultores e agricultoras e ocorre de maneira natural, representando um aspecto facilitador para a transição agroecológica e para os processos de certificação orgânica.

A comercialização é realizada principalmente em feiras livres, local em que a diversidade de produtos é característica marcante. Outro componente presente nas feiras e que faz parte da identidade do Vale é o artesanato, em especial com argila (RIBEIRO et al., 2014).

Neste terreno e acrescentando as demandas por ações de convivência com a seca intensificada pela ocupação das chapadas pela monocultura de eucalipto, foi criado, em 1994, o Centro de Agricultura Alternativa Vicente Nica (CAV), que teve como base a força do Sindicato dos Trabalhadores Rurais de Turmalina, apoiado por organizações não-governamentais e a Igreja Católica. A entidade possui como missão a realização de ações que contribuam com o desenvolvimento da agricultura familiar e aqui destacamos aquelas que permitam a melhoria da qualidade de vida 
das famílias e a proteção ao meio ambiente. Desde sua criação, as ações têm como base os valores da instituição, que considera o protagonismo, a solidariedade, a transparência e o respeito às diversidades culturais, políticas e sociais (CAV, 2015; CAV, 2020). Estas ações dialogam com a recuperação de áreas degradadas, com a implantação de sistemas agroflorestais, com a produção agroecológica, a geração de emprego e renda, a proteção aos recursos hídricos e a convivência com a seca, com destaque para o programa um milhão de cisternas (P1MC), dentre outros (CAV, 2020).

A criação do SPG Orgânicos Jequitinhonha ocorreu para suprir as demandas das famílias da região, e foi consequência dos valores que embasam o funcionamento do CAV e dos princípios que direcionam o funcionamento de um sistema participativo. A partir desta união de fatores, começou a ser gestado o SPG Orgânicos Jequitinhonha, que materializou os procedimentos participativos para avaliar a conformidade dos sistemas de produção em relação às normas de produção orgânica no país, com vistas a estabelecer garantias para a sociedade da qualidade dos produtos e fortalecer o associativismo e a produção agroecológica presente no território.

O SPG Orgânicos Jequitinhonha foi constituído em 2016 e tem atuação no Vale do Jequitinhonha, Minas Gerais, ao todo são 19 agricultores certificados, sendo todos agricultores familiares ${ }^{8}$.

Com o objetivo de proporcionar mais interação entre os agricultores, assim como facilitar a participação nas atividades de avaliação da conformidade e proporcionar a gestão horizontal, o SPG Orgânicos Jequitinhonha se organiza em núcleos no território, sendo que cada núcleo possui um coordenador. Há seis núcleos de certificação, sendo que em quatro deles os agricultores são certificados e dois deles há agricultores em processo de certificação. A definição de núcleo ocorre em função da proximidade geográfica para diminuir distâncias e tempo de viagem para participação nas atividades.

A Figura 01 apresenta a localização dos núcleos de certificação do SPG Orgânicos Jequitinhonha.

Em geral, o controle social exercido pelos agricultores e agricultoras de cada ocorre pela realização de reuniões, visitas de pares e de verificação, realização de feiras semanais e dias de campo.

\footnotetext{
${ }^{8}$ De acordo com os critérios estabelecidos na Lei 11.326 de 2006 conhecida como Lei da Agricultura Familiar.
} 
Figura 01 - Área de atuação e localização dos núcleos de certificação ligados ao Sistema Participativo de Garantia Orgânicos Jequitinhonha.

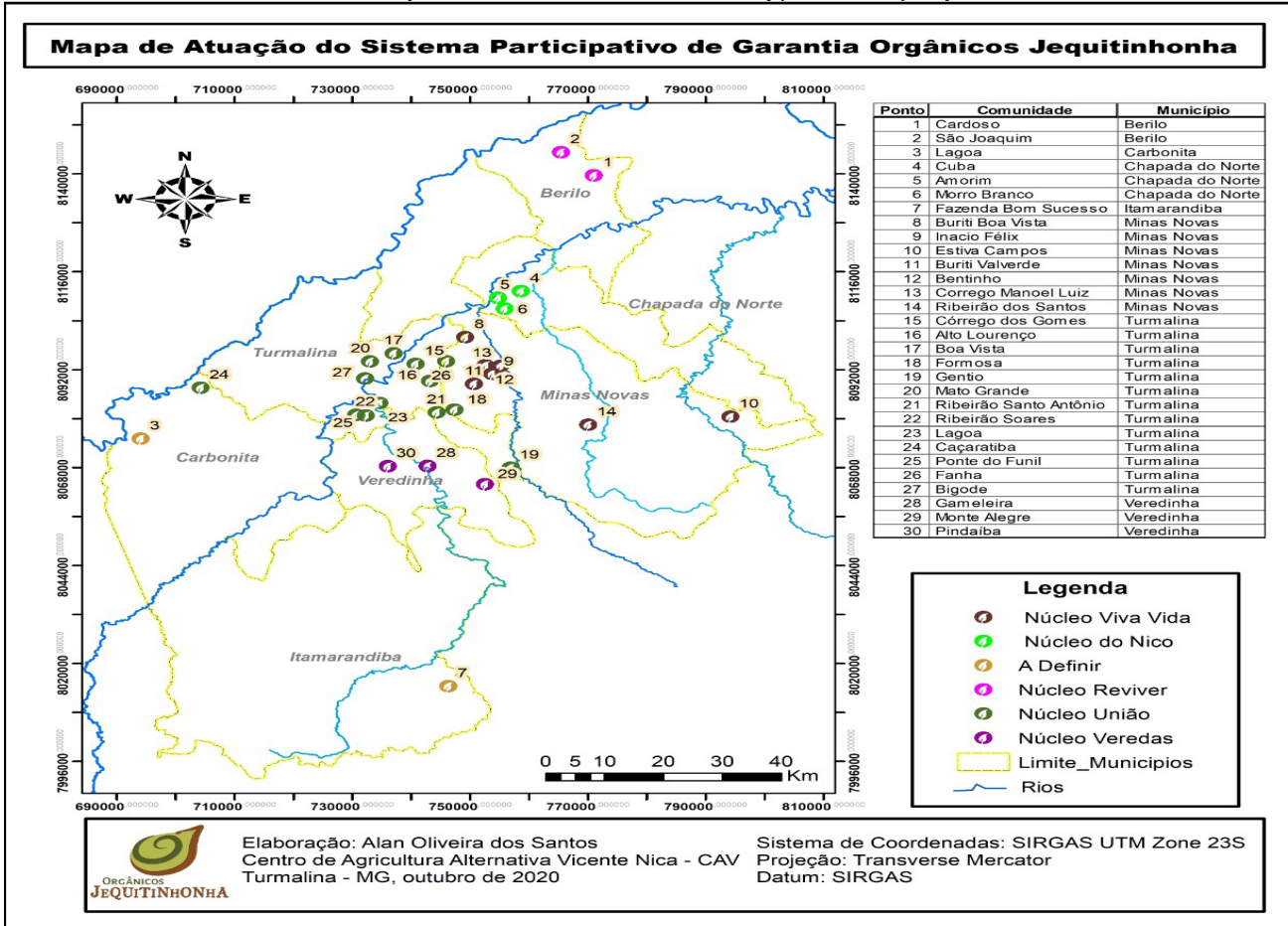

Fonte: Alan Oliveira dos Santos (2020).

\section{Procedimentos Metodológicos}

Este trabalho foi desenvolvido no SPG Orgânicos Jequitinhonha seguindo as orientações da pesquisa-ação enquanto metodologia de pesquisa. A pesquisaação é um procedimento de investigação-ação que utiliza técnicas de pesquisas reconhecidas para descrever os efeitos das mudanças de uma ação na prática (TRIPP, 2005). Essa metodologia de pesquisa exige a participação dos pesquisadores na resolução do problema ou ação investigada e está centrada no agir participativo e na ideologia de ação coletiva (BALDISSERA, 2001). A pesquisa-ação segue uma sistemática cíclica e pode variar de caso a caso. Nesta pesquisa, seguimos as seguintes etapas:

- diagnóstico da situação-problema na prática que se pretendia resolver;

- Planejamento da acão;

- Desenvolvimento do planejamento;

- Monitoramento do processo e avaliação dos resultados. 
O uso da pesquisa-ação enquanto metodologia foi possível devido o envolvimento e a participação dos autores deste trabalho na atividade pesquisada, visto que cinco dos sete autores são membros colaboradores do SPG Orgânicos Jequitinhonha. O uso desta metodologia também se justifica pelo compromisso de melhoria contínua do processo de avaliação da conformidade orgânica que agricultores e colaboradores assumiram ao constituíram o SPG.

\section{Trajetória da PESQUisa}

Esta pesquisa foi realizada no período de março a setembro de 2020 eenvolveu 29 fornecedores do SPG Orgânicos Jequitinhonha. Todas as informações que subsidiaram esta pesquisa foram coletadas mediante a participação dos autores nos processos de avaliação da conformidade orgânica, cuja problemática diagnosticada ocorreu em março de 2020.

As discussões foram realizadas e acompanhadas por meio de um grupo no Whatsapp. A realização das visitas remotas de pares aconteceu de abril a maio de 2020, sendo registradas por meio de vídeos, fotos, áudios e textos que foram sendo produzidos durante as visitas e organizados e analisados, posteriormente, pelos membros colaboradores. As discussões geradas nas visitas de pares foram sistematizadas em um relatório e assim pudemos avaliar, em conjunto com os agricultores, os resultados da ação.

\section{AS VISITAS REMOTAS NO SPG ORGÂNICOS JEQUITINHONHA}

As visitas remotas enquanto adequação das visitas de pares no processo de avaliação da conformidade orgânica cumpriu seus objetivos, em especial o de proporcionar condições para a garantia da qualidade orgânica dos alimentos, o de identificar não conformidades, promover a troca de experiências, além de promover maior interação entre os agricultores, diminuindo a sensação de isolamento social, procurando manter viva a dinâmica de participação e responsabilidade solidária entre os membros no SPG Orgânicos Jequitinhonha.

No SPG Orgânicos Jequitinhonha, as visitas constituem o principal meio de verificação da qualidade de seus procedimentos. Antes do período de pandemia da Covid-19, as visitas aconteciam de forma presencial, em duas etapas por ano.

As unidades de produção estão localizadas no Vale do Jequitinhonha em Minas Gerais, nos municípios de Turmalina, Veredinha, Minas Novas e Chapada do Norte e, mais recentemente, houve a inclusão de dois núcleos, um referente ao município de Berilo e outro núcleo com a junção dos municípios de Carbonita e Itamarandiba. Os procedimentos de avaliação da conformidade orgânica realizados por meio das visitas contaram com a participação de membros da mesma localidade e de 
membros de outros municípios, para garantir a tomada de decisões de forma mais coletiva e participativa.

Com o avanço da pandemia e o aumento dos casos da Covid-19 nos municípios do Vale do Jequitinhonha, sobretudo a partir do mês de março de 2020, todas as visitas às unidades produtivas e outras atividades coletivas e presenciais foram suspensas, evitando assim a aglomeração de seus membros. Os agricultores, em sua maioria, apresentam algum fator de risco em relação à doença, principalmente possuírem idade avançada. Além disso, por meio de ofício subsequente, o MAPA recomendou aos Organismos Participativos de Avaliação da Conformidade a suspensão dos processos de certificação que estavam em estágios iniciais e a prorrogação da validação dos certificados dos membros que não apresentaram não conformidades em visitas anteriores (MAPA, 2020b). O MAPA sugeriu também que cada organismo avaliasse o grau de risco para realização dos procedimentos em cada uma de suas regiões de atuação.

Diante do cenário configurado pela pandemia, agricultores e técnicos perceberam a necessidade de repensar seus procedimentos. O SPG Orgânicos Jequitinhonha, desde a sua formalização, vem se destacando no comprometimento de seus membros para a execução de seus procedimentos de avaliação, condição, inclusive, descrita no relatório de manutenção do credenciamento do OPAC de 2017: "Percebe-se seriedade nos procedimentos e comprometimento dos membros com as práticas agroecológicas".

Esta pesquisa que foi iniciada pelo diagnóstico da situação-problema da prática a ser desenvolvida e, a partir de então, seguiu um novo ciclo de ações, conforme descrito na sequência.

\section{A) O diagnóstico}

A situação de isolamento social e a não realização das atividades coletivas presenciais passou a preocupar os membros do SPG, pois, a realidade imposta poderia comprometer, de forma significativa, não só a qualidade dos procedimentos de verificação, mas as valiosas trocas de conhecimento e as relações de cooperação entre os seus membros. Aliado a isso, alguns membros, sobretudo aqueles em estágio inicial de transição, relataram desmotivação e dificuldades em prosseguir com as práticas agroecológicas sem a colaboração do grupo.

\section{B) O PLANEJAMENTO}

Diante da necessidade de superar a situação, alguns agricultores que assumem papel de liderança no SPG em interação com os técnicos do CAV iniciaram diálogo para construir uma estratégia que possibilitasse a continuidade das ações coletivas de forma segura para a saúde dos envolvidos, sem prejuízo para a continuidade das 
práticas participativas e agroecológicas.

Embora o uso de redes sociais e grupos de conversa no Whatsapp sejam muito utilizados atualmente, ainda não eram práticas comuns entre os membros do SPG Orgânicos Jequitinhonha. Porém, diante da impossibilidade de visitas e reuniões, a estratégia foi a criação de um grupo de Whatsapp para os membros e os colaboradores de cada um dos municípios componentes do SPG Orgânicos Jequitinhonha, visando facilitar a comunicação, a disseminação da troca de experiências e a realização das práticas coletivas de avaliação da conformidade orgânica das unidades de produção. Apesar do receio quanto à dificuldade de acesso à internet nas comunidades rurais, observamos que a participação dos agricultores e agricultoras ocorreu de forma bastante significativa e a interação entre eles se dava em diversos momentos do dia, sobretudo, no início do período noturno, com a finalização das atividades produtivas nas propriedades.

Com a aproximação do período em que comumente são realizadas as visitas de pares na região, houve a proposição, por parte da coordenação dos núcleos e de técnicos do CAV, de realização das visitas remotas, no ambiente virtual do grupo de Whatsapp do SPG Orgânicos Jequitinhonha. A sugestão foi para que todos os membros, de alguma forma, pudessem participar da execução da atividade. Para os membros já certificados a visita remota teria a finalidade de renovação ou não dos certificados e para os que se encontravam no período de conversão para o sistema orgânico a visita teria a finalidade, dentre outras, de acompanhar o processo de transição. Os membros acordaram que todos os membros do grupo de Whatsapp teriam a responsabilidade de acompanhar as visitas. A princípio alguns membros demonstraram bastante insegurança com a realização do procedimento virtual, sobretudo pela dificuldade de lidar com os equipamentos celulares e com a instabilidade da internet nas comunidades. Entretanto, observamos uma abordagem bastante solidária por parte da maioria dos integrantes, que reafirmaram o compromisso de que nenhum fornecedor seria prejudicado com essas atividades, caso apresentassem dificuldades com o procedimento.

Para a realização das visitas remotas o grupo elegeu, no ambiente virtual, coordenadores para cada dia de visitas, os quais ficariam responsáveis por conduzir o procedimento e fomentar o diálogo entre os membros. O grupo elaborou também uma agenda de apresentações e um roteiro para orientar a gravação do material pelos agricultores, contendo as seguintes informações:

- a situação das áreas certificadas e paralelas;

- a comercialização dos produtos, sobretudo em tempos de isolamento;

- a atualização dos registros da unidade de produção;

- a entrada e o uso de insumos nas propriedades;

- as medidas de cuidados com o solo, a água, a vegetação nativa e os resíduos 


\section{sanitários;}

- o relato da família sobre a importância de obterem a renovação dos certificados.

Para cada dia foi agendada a apresentação de dois fornecedores do mesmo município. Tendo como base as orientações do MAPA, ficou acordado que os fornecedores que não haviam recebido visitas presenciais anteriormente, ou que, mesmo tendo sido visitados, apresentassem algum risco de descumprimento dos princípios da produção orgânica, não poderiam ser certificados por meio do procedimento virtual, ficando assim, sem poder receber o certificado.

\section{C) A realizaÇão das visitas remotas}

As visitas remotas realizadas pelo SPG Jequitinhonha tiveram a participação de 21 agricultores visando a renovação dos certificados e oito agricultores que, por se encontrarem no início do processo, não seriam certificados por meio da visita remota, porém, participaram das visitas com o intuito de apresentarem a situação de avanço no processo de transição e os resultados da adoção das práticas agroecológicas, além de troca de experiências. Para a apresentação das unidades de produção, cada agricultor enviou áudios, fotografias e vídeos, em horários prédeterminados para os membros. Todo o material enviado foi avaliado e discutido pelos demais membros do núcleo. A duração das visitas, em sua maioria, foi de cerca de cinco horas, a depender do sinal da internet nos locais. Ao todo, 52 pessoas participaram das visitas remotas, mediadas pela assessoria técnica do CAV. A participação dos membros ocorreu no grupo de Whatsapp por meio de manifestações de opinião, sugestões, dúvidas e compartilhamento de experiências em relação à situação dos fornecedores avaliados. O perfil dos membros do grupo caracteriza-se principalmente por membros das famílias fornecedoras, esposas, maridos, filhos e colaboradores.

\section{D) O MONitoramento DO PROCESSO}

As informações compartilhadas pelos agricultores e agricultoras e demais participantes das visitas de pares remotas, bem como a decisão sobre a condição das unidades de produção foram registradas em ata, com a participação dos colaboradores que salvaram os arquivos digitais para posterior consulta. Apesar de alguns agricultores terem apresentado dificuldades com a internet, todos executaram a atividade com êxito e enviaram informações suficientes para subsidiar a avaliação da condição das unidades de produção. O processo se deu de forma participativa com o envolvimento de homens, mulheres, jovens e idosos que superaram as dificuldades com o uso da tecnologia, da escrita e da comunicação e contribuíram 
de forma efetiva na tomada de decisão pela certificação de 19 fornecedores e pela suspensão dos certificados de dois fornecedores pelo cometimento de não conformidades.

\section{E) A AValiação}

Segundo a avaliação, das visitas remotas de pares, feita pelos agricultores, o procedimento virtual gerou mais confiabilidade, uma vez que, os fornecedores repassaram todas as informações solicitadas de forma transparente e houve a participação de maior número de pessoas, em especial o envolvimento de outros membros da família, quando comparado às visitas presenciais. A transparência e a confiabilidade produzidas pelas ações coletivas são primordiais para a manutenção da credibilidade nos Sistemas Participativos de Garantia. Houve a sugestão, inclusive, da continuidade do uso dos procedimentos virtuais em outras etapas futuras, quando houver quaisquer dificuldades de realização das atividades presenciais, como em períodos chuvosos que dificultam o acesso a algumas propriedades. Além disso, o método remoto pode diminuir significativamente os custos de deslocamento entre as unidades de produção e facilitar o envolvimento de membros localizados em unidades mais distantes.

Observamos que os agricultores permaneceram no ambiente virtual do grupo de Whatsapp, mesmo após a finalização do período das visitas de pares remotas, promovendo constante diálogo sobre os aspectos produtivos, compartilhando fotos, vídeos e áudios com relatos sobre as suas experiências, no período entre as visitas. Estas relações diárias, embora virtuais, têm colaborado para a execução do controle social no SPG Orgânicos Jequitinhonha e para a diminuição da sensação de isolamento nos núcleos neste período de pandemia que antes eram habituados a se encontrarem com frequência, sobretudo em momentos de reuniões, intercâmbios e capacitações.

Na Figura 2 é possível visualizar as fases da pesquisa-ação em que o procedimento adotado foi realizado e acompanhado.

Tendo por base a análise dos resultados dessa pesquisa-ação, que buscou superar o desafio por meio da intervenção, acompanhamento e avaliação da ação na prática, e levando em conta esse ciclo, o momento atual é de novo planejamento das ações..

$\mathrm{Na}$ etapa de planejamento, que reinicia o ciclo da investigação ação, analisamos que a situação imposta pela pandemia provocou agricultores e técnicos a construírem e ressignificarem a participação. Recorremos à Bordenave (1983) para compreender o significado da participação; 
Figura 2 - Representação das fases da pesquisa-ação na realização das atividades.

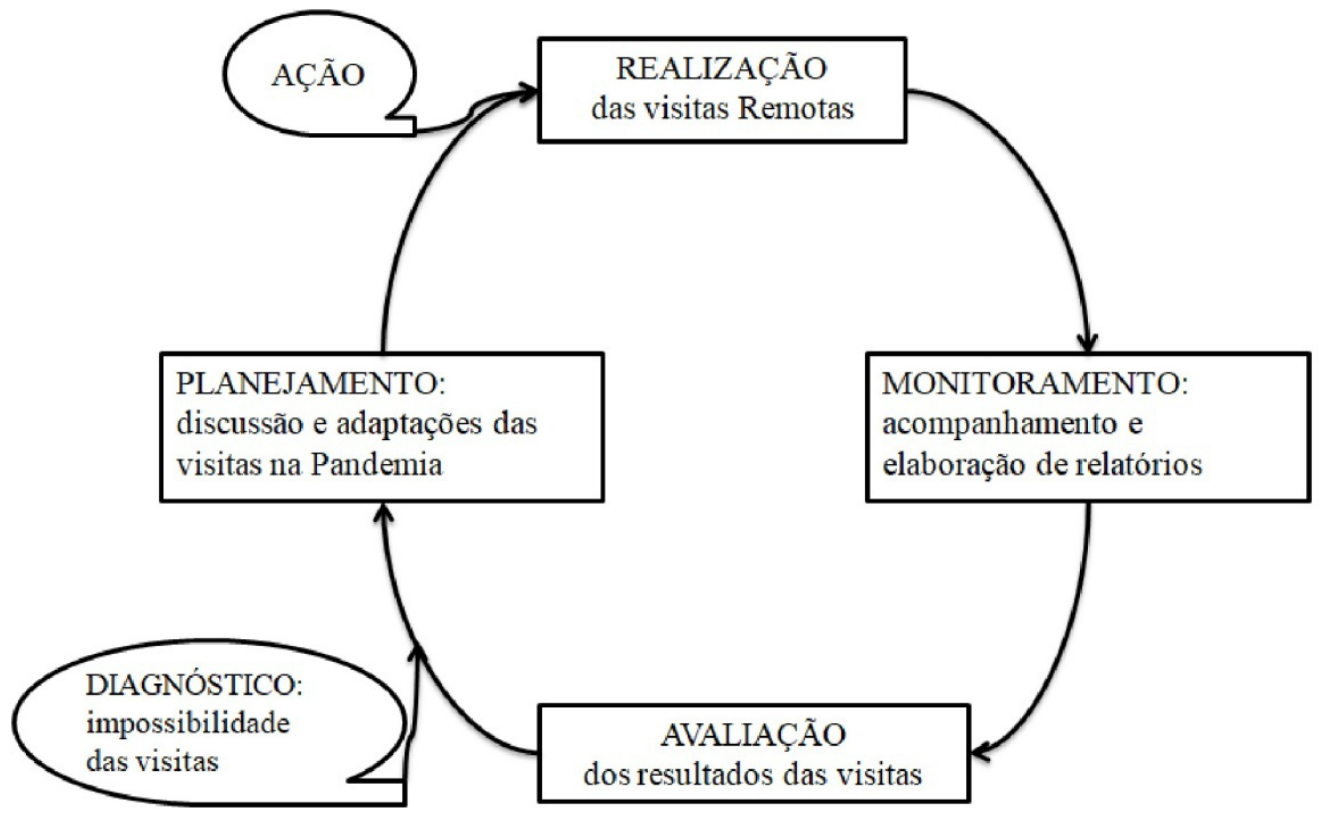

Fonte: Elaboração dos autores.

Bulhões faz parte do nosso grupo mas raramente toma parte das reuniões; Fazemos parte da população do Brasil, mas não tomamos parte das decisões importantes; Edgar faz parte da nossa empresa, mas não tem parte alguma no negócio (BORDENAVE, 1983 p. 22).

Nesse sentido, consideramos que todos os agricultores membros de um determinando núcleo de certificação participativa deveriam, não só fazer parte do grupo de Whatsapp e acompanhar a visita remota do companheiro, mas também uma participação ativa, por meio de sua manifestação, ou seja, tomar parte das decisões. Sua participação poderia ser manifestada de diferentes formas, como enviar mensagem escrita, áudio ou mesmo um símbolo. Assim, um "ok", um "de acordo" ou até mesmo um símbolo de "afirmativo" passou a significar uma participação ativa.

Nesta pesquisa-ação, analisamos também o nível da participação, pois, mesmo uma participação ativa pode conter diferenças na qualidade da participação. De novo recorremos a Bordenave (1983), para quem "a prova de fogo da participação não é quanto se toma parte, mas como se toma parte” (BORDENAVE, 1983, p.23). Neste sentido, em primeiro lugar, o grupo analisou que a participação não é uma condição igual para todos. Se para alguns era simples enviar uma mensagem fa- 
zendo uma observação ou comentando os vídeos da visita, para outros não essa situação não era tão simples. Um símbolo de afirmativo, conhecido no Whatsapp como like, já era suficiente devido às condições de escolaridade e familiaridade com a tecnologia. Outro ponto analisado nesta experiência foi o nível de participação. Assim, não é sobre a quantidade de likes ou comentários e áudios que foram enviados, mas o que significa cada manifestação. $O$ fato de ter havido duas suspensões por não conformidades detectadas durante as visitas remotas e o grupo ter identificado, manifestado e decidido pela suspensão, conforme acompanhado e monitorado, indicou que, mais do que fazer parte, os agricultores tomaram parte das decisões, inclusive de decisões difíceis como esta, a de suspender o certificado de um companheiro.

\section{Considerações Finais}

O funcionamento de um Sistema Participativo de Garantia traz consigo a necessidade do controle social por meio da participação ativa dos membros do sistema. É por meio desta participação que são gerados princípios como a confiança e a transparência sobre as ações realizadas. Decidir sobre a realização de visitas de pares remotas, mesmo diante do conhecimento dos desafios a serem enfrentados, em especial sobre o uso da tecnologia por agricultores e agricultoras, demonstra compromisso e seriedade dos membros do SPG Orgânicos Jequitinhonha em relação aos procedimentos de avaliação da conformidade e da manutenção da qualidade dos mesmos.

A realização das visitas remotas, além do atendimento de forma satisfatória dos parâmetros legais para o funcionamento de um OPAC, possibilitou em soma, a integração dos membros reduzindo a sensação de isolamento durante a pandemia da Covid-19, promovendo motivação para os agricultores. A troca de experiências promovida por meio do compartilhamento dos vídeos, fotos ou descrições detalhadas das unidades de produção foi destacada pelos participantes como estratégia que gerou maior aproximação entre eles, em especial, daqueles que estão chegando.

$\mathrm{O}$ acesso às tecnologias digitais e a incorporação destas às ações cotidianas dos agricultores e agricultoras do SPG Orgânicos Jequitinhonha, vistas inicialmente como uma dificuldade que poderia promover exclusões, evidenciou a capacidade e a determinação com a continuidade das ações dos agricultores. O processo foi marcado pela superação das dificuldades que iniciaram desde a falta de um aparelho de telefone celular ou do acesso à internet, até mesmo à falta de habilidade com o uso da tecnologia. A superação foi possível pela aquisição do aparelho, pela contratação de planos para uso de internet e até mesmo pela inclusão de novos 
membros para fortalecer a participação da família. Cada superação foi considerada pelos membros como comprometimento com o sistema (no caso de adquirir um aparelho ou internet) e também uma conquista, como nos casos de adesão dos jovens e apropriação da tecnologia pelos mais velhos.

Outro fator relevante refere-se à multiplicação da experiência que em pouco tempo chegou a outros SPGs do país. Após a experiência ter sido compartilhada com o Ministério da Agricultura e com representantes de outros sistemas participativos, logo surgiram as solicitações de compartilhamentos detalhados do processo para possibilitar a implantação e adaptações para outras regiões.

Notamos que as adversidades que poderiam ter sido danosas à credibilidade do sistema, proporcionaram resultados positivos, onde o resultado mostrou que a criatividade e o pensamento coletivo podem fazer a diferença. Neste aspecto, a previsão de adaptação dos métodos de geração de credibilidade constante do Art. 68 da IN 19/2009 (BRASIL, 2009), atuou como importante aliada, não prejudicando a livre atuação do SPG, que pode, a partir de uma realidade nova e desfavorável, construir uma solução inovadora, possibilitando a participação de todos.

Por fim, são comuns os questionamentos sobre como será a realização das práticas de avaliação da conformidade orgânica nos SPGs após o fim da pandemia. Certamente não há resultados suficientes para uma proposta de substituição total dos procedimentos presenciais pelos processos remotos, porém, é passível de compreensão que as ferramentas ora disponíveis passarão a fazer parte do cotidiano dos OPACs em situações pontuais de adversidades, promovendo a aproximação dos membros na realização das atividades e garantindo as condições para a manutenção dos princípios e das características que embasam o sistema participativo.

\section{Agradecimentos}

Aos agricultores e agricultoras do SPG Orgânicos Jequitinhonha, ao Centro de Agricultura Alternativa Vicente Nica, ao Instituto Federal de Educação, Ciência e Tecnologia do Sul de Minas e à Universidade Estadual de Campinas/Faculdade de Engenharia Agrícola pelo apoio na realização deste trabalho.

\section{REFERÊNCIAS}

AQUINO, Estela ML et al. Medidas de distanciamento social no controle da pandemia de COVID-19: potenciais impactos e desafios no Brasil. Ciência \& Saúde Coletiva, v. 25, p. 2423-2446, 2020.

BALDISSERA, A. Pesquisa-ação: uma metodologia do "conhecer" e do "agir" 
coletivo. Sociedade em Debate, Pelotas, v.7, n.2, p.5-25, Ago. 2001. Disponível em: http://revistas.ucpel.edu.br/index.php/rsd/article/viewFile/570/510. Acesso em: 23 out. 2020.

BORDENAVE, J.E.D. O que é participação. São Paulo: Brasiliense, 1983.

BRASIL. Ministério da Agricultura, Pecuária e Abastecimento. Cadastro Nacional de Produtores Orgânicos. Brasília, DF: Ministério da Agricultura, 2020. Disponível em: https://www.gov.br/agricultura/pt-br/assuntos/sustentabilidade/ organicos/arquivos-organicos/CNPO_MAPA_31_10_20202.xlsx. Acesso em: 01 nov. 2020.

BRASIL. Ministério da Agricultura, Pecuária e Abastecimento. Instrução Normativa 019, 2009. Aprova os mecanismos de controle e informação da qualidade orgânica. Disponível em: http://sistemasweb.agricultura.gov.br/sislegis/ action/detalhaAto.do? method= consultarLegislacaoFederal. Acesso em: 28 abr. 2015.

BRASIL. Ministério da Agricultura, Pecuária e Abastecimento. Ofício circular 012/ CPO/DTEC/SDA/MAPA. Brasília, DF: Ministério da Agricultura, 17 mar. 2020a.

BRASIL. Ministério da Agricultura, Pecuária e Abastecimento. Ofício circular 015/ CPO/DTEC/SDA/MAPA. Brasília, DF: Ministério da Agricultura, 15 abr. 2020b.

CAV. Centro de Agricultura Alternativa Vicente Nica. Boletim Vale Saber: Boletim Informativo Mensal, Edição nº 58, Ano 06, jan. 2015. Disponível em: https://www. admin.cavjequi.org/uploads/1ace8506561141e5bd2055b5746f98c0.pdf. Acesso em 31 out. 2020.

CAV. Centro de Agricultura Alternativa Vicente Nica. Histórico. Disponível em: https://www.cavjequi.org/sobre. Acesso em 31 out. 2020.

CHAPARRO-AFRICANO, A.-M., \& NARANJO, S. E. Participatory system of guarantees - PSG of the Red de Mercados Agroecológicos de Bogotá Región RMABR. A contribution to the sustainability of agroecological producers and markets. International Journal of Agricultural Sustainability, 18:6, 456-472, 2020. DOI: $10.1080 / 14735903.2020 .1793614$ 
DEMO, P. Participação é conquista: noções de política social participativa. São Paulo: Cortez, 2009, 1-176.

FERNANDES, S.G.; OLIVEIRA, D.; SILVA, A.G. Sistema participativo de garantia “Orgânicos Jequitinhonha”. p. 162-167. In: HIRATA, A.R.; ROCHA, L.C.D. Sistemas participativos de garantia do Brasil: Histórias e Experiências. Orgs. - Pouso Alegre/MG : 2020. 225p il..

HIRATA, A.R.; ROCHA, L.C.D.; ASSIS, T.R.P.; SOUZA-ESQUERDO, V. F..; BERGAMASCO, S.M.P.P. The Contribution of the Participatory Guarantee System in the Revival of Agroecological Principles in Southern Minas Gerais, Brazil. Sustainability, 11, no. 17: 4675, 2019. https://doi.org/10.3390/su11174675

HOME, R.; BOUAGNIMBECK, H.; UGAS, R.; ARBENS, M.; STOLZE, M. Participatory guarantee systems: organic certification to empower farmers and strengthen communities. Agroecology and Sustainable Food Systems, v.41, n.5, p.526-545, 2017. DOI: 10.1080/21683565.2017.1279702

KIRCHNER, C. Participatory Guarantee Systems (PGS): How PGS can Intensify Knowledge Exchange Between Farmers. In.: IFOAM Organic World Congress 2014, 'Building Organic Bridges', Annals... 13-15 October, Istanbul, Turkey, 2014.

KOMORI, O.M.; PRATA, V.G.; PEDROSA, R.A.; RIBEIRO, A.P.; CARNEIRO, C.; ROCHA, R. Associação dos Produtores orgânicos do Mato Grosso do Sul: da auditoria ao sistema participativo de garantia. p. 169-175. In: HIRATA, A.R.; ROCHA, L.C.D. Sistemas participativos de garantia do Brasil: Histórias e Experiências. Orgs. - Pouso Alegre/MG : 2020. 225p il..

RIBEIRO, E.M.; AYRES, E.B.; GALIZONI, F.M.; ALMEIDA, A.F.; PEREIRA, V.G. Programas Sociais, Mudanças e Condições de Vida na Agricultura Familiar do Vale do Jequitinhonha Mineiro. Revista de Economia e Sociologia Rural, Piracicaba-SP, v.52, n.02, p.365-386, Abr/Jun 2014. DOI: https://doi.org/10.1590/ S0103-20032014000200009.

TRIPP, D. Pesquisa-ação: uma introdução metodológica. Educação e Pesquisa, v.31, n.3, p.443-466, set./dez. 2005. Disponível em: https://doi.org/10.1590/S151797022005000300009. Acesso em 28 out. 2020. 